\title{
O ocidente como responsável pelas crises da Ucrânia e da Geórgia
}

\author{
The west as responsible for the crises \\ of Ukraine and Georgia
}

Rev. Bras. Est. Def. v. 5, nº 2, jul./dez. 2018, p. 113-136 DOI: $10.26792 /$ RBED.v5n2.2018.75035

\section{FRED LEITE SIQUEIRA CAMPOS IURI ENDO LOBO BEATRIZ MARCONDES DE AZEVEDO}

\section{INTRODUÇÃO}

O pós-Guerra Fria, na Europa, configurou-se como uma dualidade. Por um lado, os Estados Unidos saíram do período da bipolaridade como a única superpotência do globo e viveram um momentum imperial, o que se refletiu na estratégia de integração das repúblicas da extinta União Soviética à esfera de influência ocidental (Bandeira 2013). Por outro lado, debilitada devido ao esfacelamento da União Soviética, a Rússia viu os países que anteriormente compunham a esfera de influência soviética se aproximarem e adotarem padrões político-econômicos do Ocidente. Com efeito, instituições ocidentais — notadamente a Organização do Tratado do Atlântico Norte (OTAN) e a União Europeia - avançaram sobre as antigas repúblicas soviéticas. Em 1990, o governo de George H. W. Bush prometera a Mikhail S. Gorbachev, Secretário-Geral do Partido Comunista da União Soviética, que não haveria expansão da OTAN. Entretanto, tal promessa foi quebrada (Gordon 1997). Em 1994, Bill Clinton deu início à política de expansão da OTAN, a qual absorveu doze países da Europa Central e Oriental, entre 1999 e 2009 (United States 1995).

Fred Leite Siqueira Campos - Engenheiro mecânico, doutor em economia, professor associado I do Departamento de Economia e Relações Internacionais da UFSC. Coordenador do Grupo de Estudos sobre a Rússia (PRORUS). Vice-líder do Núcleo Interdisciplinar de Estudo em Gestão da Produção e Custos (NIEPC). Colaborador-articulista (área de Economia) do jornal russo PRAVDA. Avaliador do MEC (INEP-SINAES).

Iuri Endo Lobo - Bacharel em Relações Internacionais.

Beatriz Marcondes de Azevedo - Psicóloga, administradora, doutora em engenharia de produção e pós-doutora em administração da produção. 
Ressalta-se que a expansão da OTAN não veio sozinha. Ao mesmo tempo, Washington começava a promover a política de regime change (mudança de regime) nas recém-independentes repúblicas da Europa Central e Oriental - que consistia em promover "revoluções populares" ou golpes de Estado a fim de impulsionar: reformas "democráticas" (ou, mais especificamente, políticas de aproximação aos governos e às empresas do Ocidente), livre-mercado e substituição de regimes que ainda adotavam o modelo soviético (Reisman 2004; Bandeira 2013). Somadas à expansão da OTAN e à promoção das mudanças de regime, houve o alargamento da União Europeia com a incorporação de quinze novos membros, entre 1995 e 2013 (Archick and Morelli 2014).

Assim sendo, o Ocidente — isto é, Estados Unidos, Canadá e Europa Ocidental - chegou às fronteiras russas. Em 2004, a OTAN, maior ameaça à antiga União Soviética na Europa, durante a Guerra Fria, incorporou os três países bálticos: Estônia, Letônia e Lituânia, sendo os dois primeiros possuidores de fronteiras contíguas com a Rússia, a cerca de $600 \mathrm{~km}$ de Moscou. A aliança atlântica, portanto, estava se aproximando de Moscou (Mearsheimer 2014). Reforça-se, aqui, que a Rússia, naquela época, "não teve força nem condições para evitar que a OTAN continuasse a incorporar [algumas das] repúblicas” da antiga União Soviética (Bandeira 2013, 55). Por isso, o Kremlin ficou impotente em relação ao avanço do Ocidente sobre a antiga esfera de influência soviética, durante as décadas de 1990 e 2000 (Bandeira 2013).

Quando foi publicada a declaração da Reunião de Cúpula da OTAN de Bucareste, em 2008, Washington havia exagerado (Mearsheimer 2014). De acordo com a declaração, a OTAN dava boas-vindas à Ucrânia e à Geórgia, afirmando que os dois países se tornariam, mesmo que sem data prevista, membros efetivos da aliança (NATO 2008). Essa declaração foi reconhecida por Moscou como derradeira, tendo-se em vista que Ucrânia e Geórgia representavam interesse estratégico fundamental à Rússia. Deste modo, seria estrategicamente inaceitável para os russos que os dois países integrassem a OTAN, segundo o cálculo estratégico russo (Mearsheimer 2017; Kochladze 2017).

A resposta de Moscou foi clara. Quatro meses após a reunião de Bucareste, a Rússia protegeu (militarmente) minorias étnicas que se encontravam no território georgiano e que estavam sendo atacadas pelas forças armadas da Geórgia. O conflito durou cinco dias e as tropas georgianas foram derrotadas. O Kremlin reconheceu a independência dos dois enclaves étnicos da Ossétia do Sul e da Abecásia e manteve contingentes militares nos dois territórios para protegê-los de possíveis novas investidas do governo georgiano (King 2008). 
Em 2014, Moscou respondeu ao Ocidente de maneira mais dura. A Ucrânia vivia turbulências sociais desde o final de 2013, cujo estopim fora a recusa do Acordo de Associação Ucrânia-União Europeia. Ao recusar o referido acordo, optou pelo tratado de assistência econômica oferecido pela Rússia. Com apoio do Ocidente houve manifestações pró-União Europeia em Kíev, capital da Ucrânia, as quais culminaram na destituição do presidente pró-Rússia, Yanukovich. O presidente Putin, não aceitando o golpe de Estado, interveio na Ucrânia, tendo como resultado a anexação da península da Crimeia, no sul do país, ao território da Federação Russa, em março de 2014 (Plekhanov 2015; Mearsheimer 2014). A anexação ocorreu como resultado de refendo em que $97 \%$ da população votou a favor da incorporação da Crimeia à Rússia.

No mesmo ano, Mearsheimer (2014) publicou um artigo na revista Foreign Affairs intitulado "Why the Ukraine Crisis is the West's Fault" (Por que a crise da Ucrânia é culpa do Ocidente). Diferentemente do pensamento convencional, que atribui a Putin responsabilidade pela crise, o autor argumenta que o Ocidente detém a maior parcela de culpa pelo que ocorreu na Ucrânia. A razão para isso é que o Ocidente ameaçou interesse estratégico fundamental da Rússia ao buscar tornar a Ucrânia um bastião do Ocidente (na entrada de Moscou). Consonante com o pensamento de Mearsheimer (2014), quase meia década antes, Saakashvili (2010) havia proferido um discurso intitulado "Why Georgia Matters" (Por que a Geórgia importa). O argumento central de seu discurso era de que a Geórgia servia como "porta de entrada de energia” à Europa (Saakashvili 2010,7) e foi utilizada como um "laboratório de transformação europeia".

Ao tomar como foco de análise a argumentação de Mearsheimer (2014), entende-se que o autor utiliza quatro variáveis-centrais para tecer sua tese de que a culpa pela crise da Ucrânia foi do Ocidente. Segundo ele, houve: (1) expansão da OTAN; (2) alargamento da União Europeia; e (3) promoção da "democracia", acrescidas da condicionante de que (4) a Ucrânia servia como interesse estratégico fundamental à Rússia. Assim, esses fatos foram as principais motivações que ocasionaram tal crise.

Diante do exposto, sob o ponto de vista do pensamento realista e da teoria do realismo ofensivo, o objetivo do presente artigo é comparar as crises da Ucrânia e da Geórgia, a fim de demonstrar que ambas as crises podem ter sua responsabilidade atribuída ao Ocidente. No que tange aos procedimentos metodológicos, trata-se de uma pesquisa de natureza analógica, porque se inspira na semelhança entre um fenômeno conhecido - crise da Ucrânia - e outro que se quer estudar — crise da Geórgia. Quanto às técnicas de pesquisa empregadas, são utilizadas a descrição, a comparação, a análise e a síntese. Desse modo, descreveu-se os fatos ocor- 
ridos na culminação de ambas as crises procurando relacioná-las com as ideias de Mearsheimer (2001; 2014), com fins de corroborar a hipótese-central deste artigo de que as crises da Ucrânia e da Geórgia decorreram das mesmas causas.

\section{O PENSAMENTO REALISTA E A TEORIA DO REALISMO OFENSIVO}

Podem-se encontrar diversas categorizações do pensamento realista nos manuais de Relações Internacionais (Rezende 2014). Contudo, aquela que será empregada aqui é a apresentada por Mearsheimer (2001). O autor divide a tradição realista em três grupos: realismo clássico, realismo defensivo e realismo ofensivo. O que diferencia as três correntes é a resposta que cada uma oferece às perguntas: por que os Estados competem? E quanto poder eles buscam?

Ao se analisar o comportamento de um Estado, tem-se a seguinte possibilidade: se os demais Estados detêm poder militar, mas não se pode saber ao certo como o utilizarão, e não há instância à qual se possa recorrer em caso de agressão, o resultado é medo e desconfiança, pois qualquer um deles pode tomar a ofensiva em seu próprio benefício à custa dos outros. Portanto, as grandes potências vivem em constante medo. Desse modo, os Estados têm que, por meios próprios, garantir sua segurança. A esse último fato, Mearsheimer (2001) denomina "autoajuda". A conclusão a que Mearsheimer (2001) chega é que, devido ao medo e à autoajuda, agir ofensivamente em relação aos demais Estados e maximizar poder relativo é a melhor forma de garantir a própria sobrevivência. Posto de outra forma: medo + autoajuda = maximização de poder. Eis a máxima de Mearsheimer (2001, 36): "o melhor caminho para um Estado sobreviver na anarquia é tomando vantagem de outros Estados e ganhando poder à sua custa. A melhor defesa é um bom ataque”. De acordo com Mearsheimer (2001), poder sempre deriva direta ou indiretamente dos recursos militares dos Estados. Estes, por sua vez, buscam sempre que possível maximizar sua fatia na distribuição global de poder à custa de seus rivais, pois é a melhor estratégia de sobrevivência. Desse comportamento resulta competição por segurança, o que leva as grandes potências a serem sensíveis ao ganho de poder relativo de seus competidores.

\section{O AVANÇO DA OTAN}

O tratado de Washington, de 4 de abril de 1949, assinado por doze países, é considerado ato fundador da OTAN e marco o inicial da Guerra Fria (NATO 2014). Além dos doze Estados fundadores, mais quatro paí- 
ses entraram à organização, entre 1952 e 1982, somando dezesseis membros durante a Guerra Fria (RT 2014). Com o fim da União Soviética, em 1991, a configuração da balança de poder europeia foi alterada. As duas zonas de influência que eram divididas pela "cortina de ferro" (divisão da Europa em Ocidental e Oriental) se redesenharam. Nessa direção, o processo de expansão da OTAN teve suas negociações iniciadas nos últimos anos da Guerra Fria, ainda em 1990. Três meses após a queda do muro de Berlim, em fevereiro de 1990, a Alemanha Ocidental buscava a unificação com a Alemanha Oriental - o que despertou um problema com a União Soviética. Tendo-se em vista que a Alemanha Ocidental já fazia parte do pacto atlântico, a unificação faria com que todo o território alemão fizesse parte da OTAN, o que representava ameaça à União Soviética (Gordon 1997). Seria a primeira vez em que o território a leste da cortina de ferro receberia militares da OTAN, desde o início da Guerra Fria.

Em 1994, o presidente dos Estados Unidos, Bill Clinton afirmou, durante a Reunião de Cúpula da OTAN, que: não importava saber se a OTAN admitiria novos membros ou não, mas quando e como isso seria feito (United States 1995). A absorção de países da Europa Central e Oriental se tornou questão de tempo. Logo, a OTAN anunciou o lançamento de nova fase do seu processo de alargamento, já em 1995. Para Talbott (1995), tal decisão teve dois significados: um político e outro militar. Politicamente, representou que os novos membros da organização deveriam adequar-se a padrões mínimos exigidos. Assim, a expansão da OTAN significou a exportação de padrões político-econômicos ocidentais para os entrantes, no que dizia respeito à "padronização" das suas instituições e à economia de mercado. Militarmente, funcionou como mecanismo de dissuasão contra a Rússia.

Com o avanço da OTAN, portanto, além de entrar à defesa coletiva da organização, os novos membros do pacto atlântico tiveram de adotar sistemas político-econômicos compatíveis com o Ocidente, aproximando-se militar e politicamente deste (Talbott 1995). Por conseguinte, expandir a OTAN significou, em última instância tornar a Europa Central e Oriental parte do bloco ocidental, ou seja, representou a expansão da zona de influência do bloco ocidental sobre o que anteriormente era esfera de influência soviética (Mearsheimer 2014). É importante destacar que a tomada do espaço de influência soviético pelo Ocidente não poderia, de modo algum, agradar aos russos (sucessores jurídicos da União Soviética). Por isso, os líderes russos se opuseram à expansão da OTAN (Mearsheimer 2014).

O processo de alargamento da OTAN continuou ao longo dos anos de 1990 e 2000, apesar dos protestos russos. Como já destacado anteriormente, em 2008, na reunião de cúpula da OTAN, em Bucareste, a administração de George W. Bush apoiou a admissão da Ucrânia e da Geórgia na aliança, 
embora França e Alemanha se opusessem à ideia, por medo de antagonizar com a Rússia (Mearsheimer 2014; Gallis et al. 2008; Gallis 2008). No mesmo ano de 2008, quatro meses após a reunião de Bucareste, a Rússia deu seu apoio (militar) à parte da população georgiana. Esse fato, segundo Mearsheimer (2014), deveria ter sido o suficiente para dissipar qualquer dúvida sobre a determinação russa de evitar que Ucrânia e Geórgia entrassem à OTAN. Apesar da advertência, a OTAN jamais abandonou sua intenção de admitir os dois países e continuou o processo de alargamento. No ano seguinte, Albânia e Croácia foram admitidas. Na Figura 1 é apresentado o mapa das configurações da OTAN (e seus membros) em 1990 e em 2009.

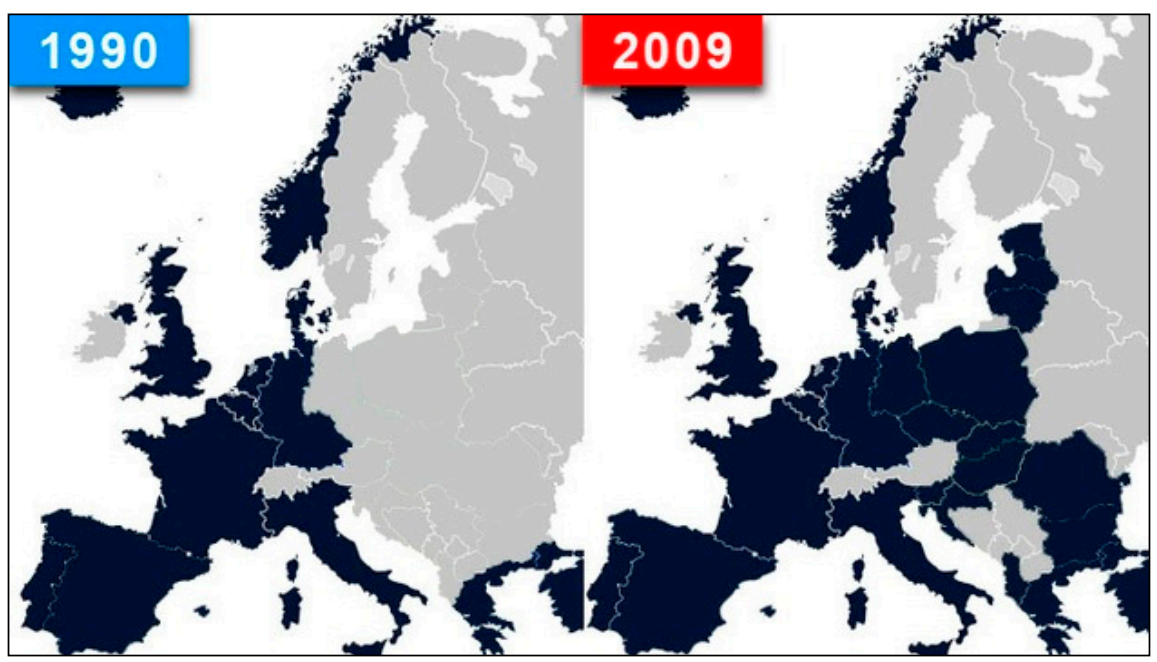

Figura 1 - Avanços da OTAN após a queda do muro de Berlim.

Fonte: RT (2014).

\section{A EXPANSÃO DA UNIÃO EUROPEIA}

A União Europeia, formalmente estabelecida em 1991, com a assinatura do Tratado Maastricht, entrou em vigor no final de 1993 (BBC 2015). Naquele ano, a organização era composta por treze membros. Nos vinte anos seguintes, totalizou vinte e oito (Archick and Morelli 2014). Destacase que todos os quinze novos membros incluídos nas quatro últimas rodadas de expansão da União Europeia estavam situados a leste da cortina de ferro. Tal informação revela como o alargamento da União Europeia - 
da mesma forma que o da OTAN - absorveu países que nos tempos de Guerra Fria viviam sob influência de Moscou.

A visão da União Europeia sobre a integração do restante do continente é que esse processo auxiliaria a "superar décadas de divisão artificial e ajudaria a tornar a Europa completa e livre" (Archick and Morelli 2014, 3). Como consequência, a Cortina de Ferro teve de ser dissolvida. Em outras palavras, a União Europeia avançou sobre a Europa Central e Oriental e a Rússia, como sucessora jurídica da União Soviética, sentiu-se pressionada por perder espaço sobre sua antiga esfera de influência. A cooperação dos membros da União Europeia inclui desde assuntos de política interna (combate à corrupção; acesso ao mercado europeu sem barreiras tarifárias e; a adoção de legislação comercial comum), até temas de cooperação multilateral, como, por exemplo, gestão integrada de fronteiras (European Comission 2017a; Park 2014).

\section{O avanço da UE e a situação da Ucrânia}

No que diz respeito à Ucrânia, especificamente, o avanço da União Europeia e o ápice da aproximação foram atingidos com o Acordo de Associação Ucrânia-União Europeia, com fins de estreitar o vínculo político e a integração econômica, além de fundar um novo estágio de relações entre as duas partes (European Union 2017b). As negociações entre as partes contratantes começaram em 2007, durante o mandato do presidente Yushchenko, que ascendera ao poder por meio da Revolução Laranja, de 2004. Em 2011, as negociações foram encerradas para que, em 2012, começasse o processo de assinatura do tratado (Ukraine 2015). Tal tratado apoiava reformas em áreas fundamentais, entre elas: reforma no sistema judiciário e administrativo, reforma em cada um dos ministérios, reforma econômica e reforma das forças armadas (Gressel 2017).

É importante destacar que, como afirma Plekhanov (2015), embora o pêndulo ucraniano Ocidente-Rússia tivesse sido direcionado para o lado ocidental (quando Yushchenko foi alçado à presidência do país, em 2005), cinco anos depois o pêndulo oscilou de volta para a Rússia. Em 2005, os índices de aprovação popular do governo Yushchenko giraram em torno de 54\%; em 2010, retraíram para cerca de 5\%. Apesar de sua tendência pró-Moscou, enquanto presidente, Yanukovich seguiu, inicialmente, diretriz de não-alinhamento externo. Mas normalizou as relações com a Rússia assinando, por exemplo, acordo de concessão de bases navais na Crimeia para a marinha russa e oficializando o uso da língua russa em nível local. No entanto, por outro lado, buscou ampliar a parceria com a OTAN e estreitar laços com a União Europeia (Plekhanov 2015). 
Nesse aspecto, Yanukovich deu seguimento às negociações sobre o Acordo de Associação Ucrânia-União Europeia, iniciado no governo de seu antecessor, Yushchenko. Durante a administração de Yanukovich, as negociações avançaram e a assinatura do acordo estava marcada para o final de novembro de 2013, na Reunião de Cúpula da União Europeia, em Vilnius, Lituânia (Plekhanov 2015). Uma semana antes de sua assinatura, o acordo foi rejeitado pelo gabinete de Yanukovich (BBC 2013). Ao invés do acordo com a União Europeia, a Ucrânia buscou fortalecer cooperação com a Rússia (BBC 2014). Algumas semanas mais tarde, o presidente russo, Vladímir Putin, ofereceu um acordo de assistência econômica à Ucrânia, concordando com a compra de US $\$ 15$ bilhões da dívida ucraniana, redução do preço do gás natural fornecido à Ucrânia em um terço e investimento no setor industrial do país (BBC 2014; Plekhanov 2015).

A recusa de Yanukovich a assinar o Acordo de Associação UcrâniaUnião Europeia, no dia 21 de novembro de 2013, foi o estopim de uma série de manifestações que se transformaram em guerra civil. As manifestações foram apoiadas/financiadas pelo Ocidente (Plekhanov 2015). A oposição, segundo Plekhanov (2015), mobilizou descontentamentos populares mediante controle das mídias de massa, uso de redes sociais e financiamento de organizações não-governamentais norte-americanas. Além disso, a oposição utilizou bandeiras nacionalistas, apresentadas como defesa da democracia, em oposição às oligarquias e à corrupção, entendendo essa mensagem como busca por independência da influência russa.

Ainda no final de novembro de 2013, milhares de manifestantes formaram os maiores protestos do país, desde a Revolução Laranja de 2004 (BBC 2013). No início do mês de dezembro, oitocentas mil pessoas ocuparam a Praça Maidan (Praça da Independência), em Kíev, pedindo o afastamento do presidente Yanukovich e a retomada das negociações com a União Europeia (BBC 2013). Os manifestantes carregavam cartazes com mensagens pró-Ocidente e, como seu símbolo, bandeiras da União Europeia. Essas manifestações lembravam àquelas da Revolução Laranja (Gressel 2017; BBC 2013).

Dessa vez, contudo, as manifestações tornaram-se violentas. Uma coalizão oposicionista de grupos militantes ultranacionalistas juntou forças para combater as investidas do governo e ocupar espaços públicos em Kíev e outras cidades. Em 22 de janeiro de 2014, ocorreram as duas primeiras mortes em protestos (Costa 2015; Plekhanov 2015; Mearsheimer 2015). No mês de fevereiro, o conflito atingiu seu clímax. Manifestantes radicais armados empreenderam investida para tomar o prédio do parlamento em Kíev. O confronto durou três dias e resultou em quase cem mortes. Tendose em vista a escalada da violência, Alemanha, França, Polônia e Rússia 
intervieram no conflito e promoveram rodada de negociações entre os dois lados (Plekhanov 2015). O resultado das negociações, acertado no dia 21 de fevereiro, determinava novas eleições em maio. Até lá, um governo de unidade nacional seria formado, uma comissão independente investigaria os casos de abuso de autoridade e violência decorrentes dos confrontos entre polícia e manifestantes, forças de segurança e grupos militantes deveriam se retirar e armas ilegalmente obtidas seriam entregues às autoridades competentes (Plekhanov 2015).

$\mathrm{O}$ acordo, no entanto, sucumbiu em questão de horas. A polícia e as forças de segurança retiraram-se do centro da cidade, como determinava o acordo. Os grupos militantes armados, por outro lado, recusaram-se a aceitá-lo e a entregar as armas, pois, exigiam remoção imediata de Yanukovich do poder. Nesse cenário, os prédios do governo que se localizavam no centro da cidade ficaram sem segurança, abertos para serem tomados. Aproveitando a oportunidade, os manifestantes ocuparam os prédios da administração presidencial (Plekhanov 2015).

Com a vitória da oposição em destituir Yanukovich da presidência, o país mergulhou ainda mais na guerra civil. O resultado das manifestações da Praça da Independência (em Kíev) engatilhou revolta no sul e leste do país. Embora os grupos nacionalistas/golpistas que tomaram o poder ucraniano detivessem apoio significativo na região oeste, as regiões sul e leste eram a favor do governo (então deposto). Após a mudança de governo, os movimentos de resistência ganharam força. No dia seguinte à destituição do presidente, lideranças políticas pró-Yanukovich do sul e leste se reuniram e a classificaram como golpe de Estado. Na sequência, o parlamento anulou a lei aprovada por Yanukovich que permitia o uso da língua russa em nível local, majoritariamente falada no sul e leste (Plekhanov 2015).

O próximo movimento realizado no conflito foi dado pela Rússia. Em resposta à queda do presidente Yanukovich, o Kremlin denunciou a nova liderança ucraniana como ilegítima (Hille 2014). No dia primeiro de março, o parlamento russo aprovou o pedido de Putin para usar a força e proteger os interesses russos na Ucrânia (BBC 2014). Seu interesse primordial era a manutenção da base naval de Sebastopol, na Crimeia. Esse porto é considerado a base da frota naval russa do Mar Negro, vital à projeção de poder naval russo para o Mar Mediterrâneo e à defesa do porto de Novorossisk - maior porto comercial da Rússia, localizado em sua costa no Mar Negro (Hille 2014).

A urgência em defender a base naval de Sebastopol decorreu da mudança de regime em Kíev. No ano de 2010, Yanukovich prolongara a concessão do uso do porto de Sebastopol pela frota naval russa até 2042, com possibilidade de extensão até 2047. Entretanto, devido à destituição do 
presidente e à ascensão de regime anti-Rússia, surgira a possibilidade de o novo governo revogar o acordo de 2010. Se a nova administração o fizesse, a frota russa da base de Sebastopol não teria mais respaldo político para se manter na Crimeia. Além do que, estaria aberto o caminho para que a Ucrânia fechasse acordo com a OTAN e esta utilizasse as bases (até então russas) em Sebastopol (Hille 2014).

Para preservá-la, portanto, os russos decidiram proteger suas posses presentes na Crimeia. Em 27 de fevereiro, os cerca de 15 mil militares russos (que tinham suas atividades na península) bloquearam os pontos de acesso do continente à Crimeia para evitar que as forças armadas ucranianas revertessem a situação (Hille 2014; Mearsheimer 2014; Costa 2015; Mearsheimer 2015; Plekhanov 2015). No dia 16 de março, foi realizado referendo de secessão da Crimeia à Rússia. O resultado do referendo apontou que $97 \%$ da população da Crimeia era favorável à sua integração à Federação Russa. Dois dias depois, Putin assinou o tratado de anexação, oficializando a integração da Crimeia (Mielniczuk 2014; Mearsheimer 2014; BBC 2014). Conforme Plekhanov (2015), tal fato deteriorou mais ainda as relações entre Rússia e Ocidente. Os governos dos Estados Unidos e diversos países europeus, como era de se esperar, condenaram a ação russa e impuseram sanções econômicas sobre a Rússia e interromperam cooperação em certas áreas. Com base no exposto, infere-se, ao observar a política de expansão da União Europeia, que o alargamento desta organização foi simétrico ao da OTAN: absorveram-se países da Europa Central e Oriental (inclusive a Ucrânia), os quais faziam parte da esfera de influência soviética.

\section{O Avanço da UE e a Situação da Geórgia}

Em termos político-econômicos, as relações bilaterais Geórgia-União Europeia vinham sendo intensificadas, desde 2003, com o lançamento da Política Europeia de Vizinhança (European Comission 2017b; European Union 2017c). No que diz respeito à "promoção da democracia”, a Geórgia viveu a Revolução Rosa, em 2003, a qual foi, também, instigada e financiada pelo Ocidente (Sussman and Krader 2008; Tucker 2007). Por fim, no quesito militar, a OTAN declarou, em 2008, sua intenção de tornar a Geórgia membro da organização atlântica (Mearsheimer 2014; NATO 2008).

Segundo Rinnert (2011), a aproximação da União Europeia com a Geórgia, inicialmente, caracterizava-se pelo desinteresse mútuo. Embora houvesse, desde 1991, inciativa de cooperação, a União Europeia não direcionava muita atenção à região do Cáucaso pela distante localização e reduzida dimensão geográfica. A Geórgia, por outro lado, independente da União Soviética, desde 1991, encontrava-se imersa em conflitos inter- 
nos. Foi apenas em 2003 que a União Europeia começou a revitalizar sua relação com a Geórgia. Neste ano, a Geórgia se tornou um dos parceiros da União Europeia. Desde então, as relações entre as duas partes se intensificaram com base no princípio de integração contínua (Rinnert 2011).

A Política Europeia de Vizinhança consistia em uma inciativa bilateral baseada em dois pilares (Rinnert 2011). O primeiro, tendo em vista a instabilidade das regiões vizinhas, era o de "promover um cinturão de países 'bem governados’ a leste da União Europeia” (European Union 2003, 8). E o segundo se alicerçava no compartilhamento dos princípios fundamentais da organização com os países vizinhos, tais como: expansão do mercado ocidental e instituições com caráter democrático ocidental (Rinnert 2011; European Comission 2017b).

Além do lançamento da Política Europeia de Vizinhança, outra força estimulou a Geórgia a se aproximar do Ocidente: a Revolução Rosa. Nesse sentido, o Ocidente, particularmente os Estados Unidos, instigaram mobilizações políticas nos três países citados por Bandeira (2013): na Sérvia, em 2000, o presidente Milosevic foi deposto; na Geórgia, em 2003, o presidente Shevardnadze renunciou à presidência; e na Ucrânia, em 2004, a eleição de Yanukovich foi invalidada. Nos três casos, o Ocidente teve papel determinante (Sussman and Krader 2008; Tucker 2007; Almeida 2008). Financiados pela organização não-governamental norte-americana Soros Foundation, ativistas georgianos visitaram Belgrado, na Sérvia, onde receberam treinamento do grupo Otpor poucos meses antes da queda de Shevardnadze, em 2003. Ao retornar à Geórgia, os ativistas georgianos formaram o grupo Kmara (Basta). Sua ideia central era tomada de poder (Antelava 2003).

A Revolução Rosa consistiu em uma série de protestos que levaram Shevardnadze a renunciar à presidência, em novembro de 2003 (Mydans 2003; Osce 2004). Como consequência da renúncia de Shevardnadze, nova eleição presidencial ocorreu, em janeiro de 2004, da qual o líder da Revolução Rosa, Saakashvili, saiu-se vencedor (Fairbanks 2004). Segundo Mydans (2003), sob o governo de Shevardnadze, que se manteve no cargo presidencial por doze anos (1992-2003), a corrupção se tornara pandêmica e a violência e a escassez cresceram.

Observa-se que os interesses ocidentais promoveram a unificação da oposição na Geórgia, assim como o fizera na Ucrânia, durante a Revolução Laranja. Desse modo, evidencia-se como o Ocidente interveio na Geórgia para: "promover a democracia", por meio da estratégia de mudança de regime expressa pela Revolução Rosa para integrá-la ao Ocidente política e economicamente, mediante cooperação com a União Europeia. O conflito na Geórgia estourou quando tropas georgianas, na noite do dia 7 de agosto 
de 2008, respondendo a um ataque vindo da Ossétia do Sul, invadiram a região separatista para retomar controle sobre o território. De acordo com Bandeira (2013, 113), "a invasão da Ossétia do Sul foi planejada pelo governo de Mikheil Saakashvili e recebeu luz verde do presidente George W. Bush". Durante a investida das tropas georgianas, no entanto, soldados russos foram mortos (King 2008). E, como resposta, a Rússia interveio a fim de defender a autonomia da Ossétia do Sul e da Abecásia (Bandeira 2013).

Conforme o relatório da União Europeia (European Union 2009), a tensão na zona de conflito vinha crescendo. No início de 2008, trocas de tiros haviam ocorrido entre os lados georgiano e osseto, incluindo artilharia pesada. Em julho do mesmo ano, ocorreu o exercício militar conjunto Immediate Response, próximo à capital da Geórgia, Tibílisi, em que mil soldados dos Estados Unidos treinaram as forças de Armênia, Azerbaijão, Geórgia e Ucrânia (Bandeira 2013). No mesmo período, tropas russas executaram exercícios militares de grande escala na região do norte do Cáucaso, próxima à fronteira Rússia-Geórgia. E, no início de agosto, dias antes do início do conflito, autoridades da Ossétia do Sul já iniciavam a evacuação de civis para território russo.

A guerra durou cinco dias, oitocentas e cinquenta pessoas foram mortas e mais de cem mil foram deslocadas (European Union 2017a). As tropas russas conquistaram a cidade de Gori e destruíram depósitos de armamentos e bases militares georgianas (Bandeira 2013). A Rússia logo reconheceu a independência das duas regiões e prometeu protegê-las. A maior parte dos países ocidentais, contudo, continuou vendo as regiões como parte da Geórgia (BBC 2009). Destaca-se que, assim como no caso ucraniano, o Ocidente avançou sobre a Geórgia - por meio da expansão da OTAN e da União Europeia. Como resposta, as ações da Rússia na Geórgia advertiram o Ocidente de que a marcha em direção à Geórgia lhe era inaceitável (Bandeira 2013; King 2008; Mearsheimer 2017). Ver mapas representativos da expansão da União Europeia na Figura 2. 


\section{A CONSTRUÇÃO DA UNIÃO EUROPEIA}

\section{ALARGAMENTOS DA UNIÃO EUROPEIA}

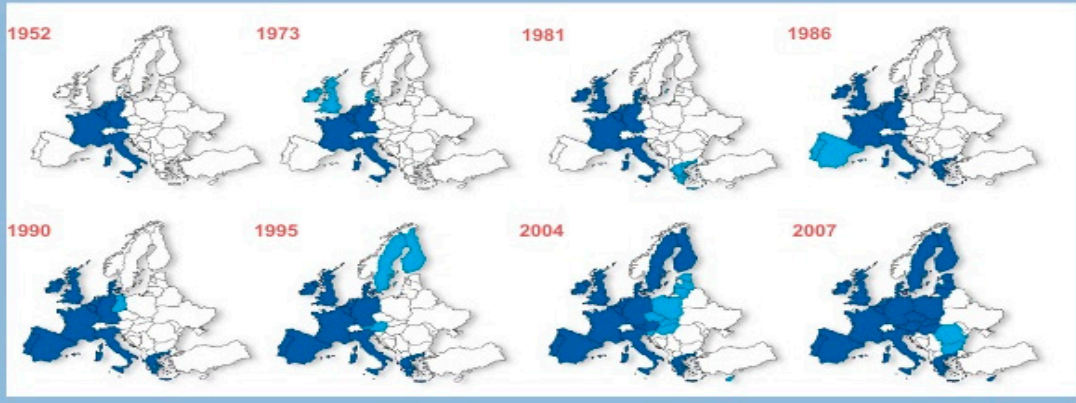

Figura 2 - O alargamento da UE (1952-2007).

Fonte: Adaptado de SlideShare — a União Europeia (2011).

\section{"PROMOÇÃO DA DEMOCRACIA"E REVOLUÇÕES COLORIDAS}

O termo "revolução colorida" foi cunhado pela mídia internacional e por pesquisadores ligados às agências de promoção da democracia do Ocidente. Segundo Sussmann e Krader (2008), as Revoluções Coloridas foram resultado de massivo planejamento e investimento por parte dos países ocidentais, principalmente dos EUA. As semelhanças existentes entre os protestos e sua difusão podem ser atribuídas aos programas de promoção da democracia e a ONGs vinculadas ao Ocidente.

Segundo Mearsheimer (2014), os EUA utilizaram como ferramenta para afastar a Ucrânia da Rússia a "promoção da democracia" e a disseminação de valores ocidentais. É importante esclarecer que a Revolução Rosa e a Revolução Laranja foram algumas entre outras "revoluções coloridas" que tomaram lugar no leste europeu e na Ásia Central, não se resumindo, portanto, a um fenômeno que atingiu a Geórgia e a Ucrânia, isoladamente, conforme ilustrado na Figura 3. Para Tucker (2007), essas revoluções tomaram lugar na Sérvia, em 2000; na Geórgia, em 2003; na Ucrânia, em 2004; e no Quirguistão, em 2005. Assim como Sussman e Krader (2008), Bandeira (2013) destaca a expressiva atuação dos Estados Unidos nesses movimentos. 


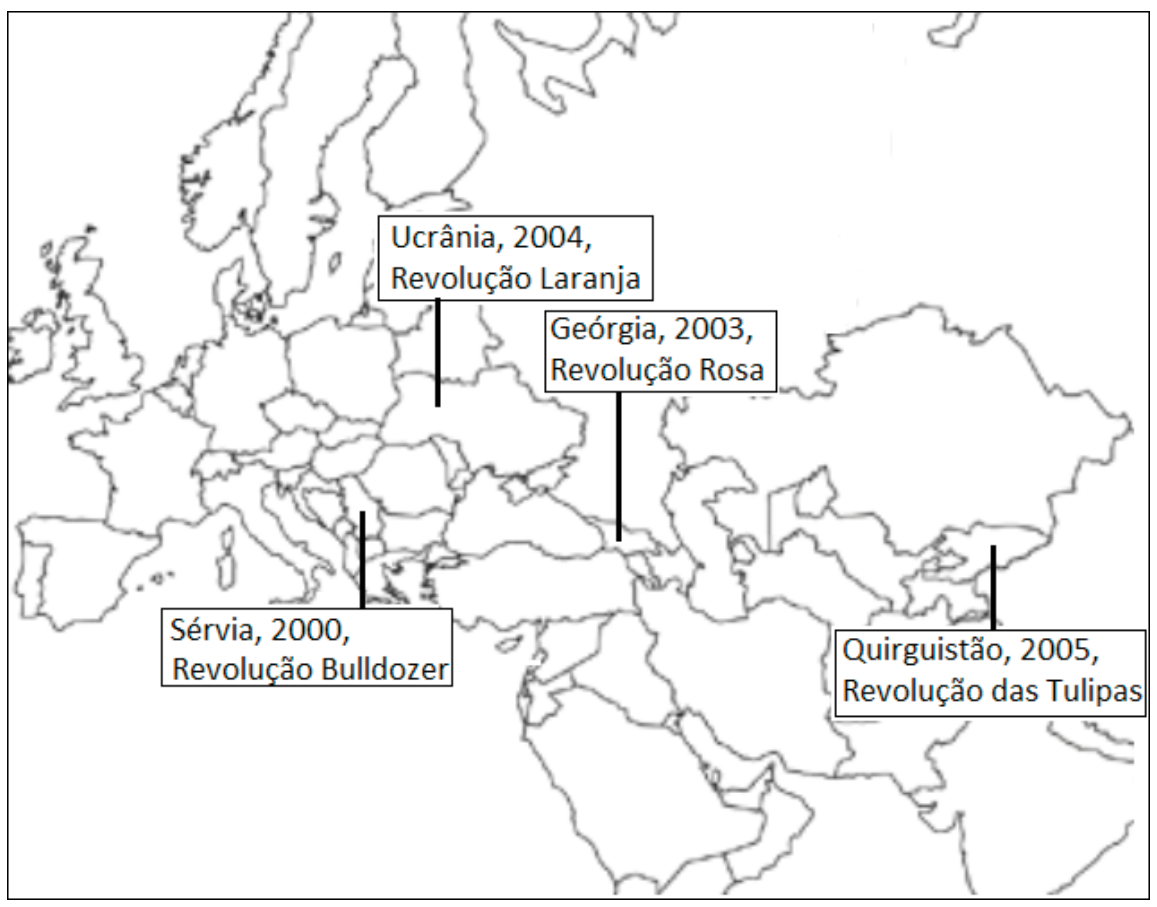

Figura 3 - Mapa das Revoluções Coloridas.

Fonte: adaptado de Tucker (2007).

As revoluções coloridas seguiram um modus operandi semelhante. Assim, o modelo de revolução que foi aplicado na Geórgia, no Quirguistão, na Sérvia e na Ucrânia consistiu-se em insurreições populares, as quais eram encorajadas, mobilizadas e instigadas pelo Ocidente para desestabilizar governos hostis aos seus interesses, mediante financiamento e treinamento de lideranças sociais nos países-alvo. Mais especificamente, a atuação estrangeira se concentrou nos âmbitos político, financeiro, técnico e publicitário.

De acordo com Sussman e Krader (2008), a influência política do Ocidente sobre as revoluções coloridas adotou duas táticas: unificação da oposição e financiamento de pesquisas de boca de urna. Em 2004, no mesmo dia da publicação do resultado oficial das eleições, dezenas de milhares de apoiadores do líder oposicionista e pró-Ocidente, Yushchenko, reuniram-se na Praça Maidan (Praça da Independência), em Kíev, alegando fraude eleitoral e pedindo anulação das eleições. Dessa forma, iniciou-se a Revolução Laranja. Protestos continuaram de modo organizado nas sema- 
nas seguintes, com tendas de alojamento, palcos para discursos e shows (Tucker 2007). Entre os manifestantes, um dos principais grupos de oposição, Pora (É Tempo), havia recebido - com auxílio financeiro ocidental treinamento do movimento da juventude sérvia, Otpor (Resistência), que fora uma das principais forças que causaram a revolução na Sérvia, quatro anos antes (Sussman and Krader 2008).

Grupos oposicionistas receberam treinamento técnico e publicitário do Ocidente para pôr em prática a revolução. A ideia era utilizar estratégias de marketing corporativo. Para isso, o grupo Pora recebeu US\$ 500 mil da Freedom House e outro grupo oposicionista chamado Znayu (Saber) recebeu US\$ 1 milhão da U.S.-Ukraine Foundation para executarem campanha publicitária contra Yanukovich em dezessete cidades da Ucrânia (Sussman and Krader 2008). A estratégia ocidental de mudança de regime aplicada na Ucrânia, em 2004, triunfou. Essa ferramenta do Ocidente de "promoção da democracia”, que foi utilizada para afastar a Ucrânia da Rússia e incorporá-la ao seu bloco, corroborou com o processo de alargamento da OTAN e com a marcha do Ocidente a leste, à custa da Rússia (Mearsheimer 2014). Esse triunfo foi idêntico aos acontecimentos na Geórgia (em 2003).

\section{POR QUE AS CRISES DA GEÓRGIA E DA UCRÂNIA TÊM SUA RESPONSABILIDADE ATRIBUÍDA AO OCIDENTE? QUAIS SÃO AS ESTRATÉGIAS RUSSAS PARA A UCRÂNIA E PARA A GEÓRGIA?}

Segundo Marshall (2015a), líderes ocidentais têm dificuldade de desvendar as ações da Rússia. Após a anexação da Crimeia, Putin foi acusado de ser irracional, de querer ressuscitar o império soviético e foi comparado a Hitler. Segundo a opinião prevalente no Ocidente, a responsabilidade pela crise da Ucrânia pode ser atribuída quase que inteiramente à Rússia. No entanto, na visão de Mearsheimer (2014), trata-se de um equívoco, uma vez que segundo ele, os Estados Unidos e seus aliados são quem detêm a maior parte da responsabilidade pela crise. Para Marshall (2015b), a intervenção russa na Ucrânia deveria ser entendida a partir da tentativa dos líderes russos de lidar com a geografia. $\mathrm{O}$ autor afirma que duas preocupações da Rússia - vulnerabilidade em terra firme e falta de portos de águas quentes - levaram à sua ação na Ucrânia, em 2014. Em virtude da planície europeia, a Rússia possuía expressiva fragilidade contra invasões terrestres (a ausência de barreira física na fronteira oeste). Por causa disto, os russos tentaram diversas vezes conquistar os territórios da planície europeia (até a Polônia) para que as forças armadas russas conseguissem bloquear o avanço de invasores com mais facilidade. No cálculo estratégi- 
co russo, portanto, o controle sobre os países que compunham a planície europeia era de vital importância para sua defesa, pois, ao controlá-los, garantia-se a zona-tampão entre sua fronteira e ameaças securitárias vindas do Ocidente pela planície europeia (Marshall 2015b; Mearsheimer 2014). Deve-se salientar, também, que, desde o fim da União Soviética, a Rússia perdera influência sobre a região e o Ocidente avançou pela planície. Assim, Ucrânia e Bielorrússia foram os dois últimos Estados-tampão entre o bloco ocidental e a Rússia - na fronteira oeste desta. Eis, então, o primeiro fator geopolítico que fez da Ucrânia interesse estratégico fundamental russo (Marshall 2015b).

Para Marshall (2015b), o segundo fator pelo qual a Ucrânia se configurou como interesse fundamental da Rússia decorreu da ausência de portos de águas quentes no território russo que tivessem acesso direto a oceano. Muitos de seus portos se localizam no norte do país e, consequentemente, tinham suas águas congeladas durante parte do ano. Os demais, como o porto de Novorossisk, no Mar Negro, e o de Vladivostok, no Mar do Japão, não tinham acesso direto ao oceano, o que não impedia o comércio, mas a capacidade da frota russa de operar como potência global (Marshall 2015b). Devido a tal escassez, o porto de Sebastopol, na Crimeia, ganhou relevância. Embora ele não tivesse acesso direto a oceano, localizava-se em águas quentes e profundas, o que permite navegação ao longo do ano inteiro, e que embarcações militares (de grande porte) possam atracar sem dificuldade, garantindo seu interesse militar no Mar Negro e sul da Rússia (Marshall 2015b; Hille 2014). Assim sendo, a Ucrânia se tornou peça fundamental no cálculo estratégico russo. Representava a zona-tampão que protege a Rússia de ameaças ocidentais e abrigava a base naval de Sebastopol. O comportamento da Ucrânia é de vital importância para a Rússia. Assim, isto explica sua decisão de anexar a Crimeia ao território russo.

Já sobre a importância da Geórgia à Rússia, em 2010, o presidente da Geórgia, Saakashvili, proferiu um discurso intitulado "Why Georgia Matters" (Porque a Geórgia importa). Segundo Sakashvili (2010), duas razões principais respondem à pergunta: o fato de a Geórgia ser vista como porta de entrada de energia à Europa e o fato dela ter se tornado um "laboratório de transformação europeia”. Esses dois pontos levantados ilustram a importância estratégica da Geórgia à Rússia. O entendimento da Geórgia enquanto porta de entrada de energia para a Europa faz referência, sobretudo, à posição geográfica do país, que está situado ao sul da Rússia e ao norte do Oriente Médio, entre o Mar Cáspio e o Mar Negro, conectando a Ásia Central à Europa. Além disso, ao saber que a bacia do Mar Cáspio possuía significativa variedade de recursos naturais, percebe-se que a Geórgia acabou desempenhando, por conectar a região do Cáspio à Europa, papel 
de rota de transporte dos recursos dessa região para o continente europeu. Essa rota (e sua importância à Rússia) fez com que os Estados Unidos avançassem sobre o Cáucaso, Ásia Central e a Geórgia com o objetivo de assegurar o fornecimento energético originado na região do Cáspio. Por conseguinte, conforme Bandeira (2013), a importância da Geórgia para o Ocidente não foi unicamente econômica, ou seja, não se limitou ao papel de rota energética entre o Cáspio e o Ocidente. A importância da Geórgia foi vista como geoestratégica, pois o estabelecimento dessa rota pelo território da Geórgia e do Azerbaijão desviava da Rússia e do Irã o monopólio das rotas de fornecimento energético da Ásia para a Europa.

Em virtude da preocupação do Ocidente com a vulnerabilidade do abastecimento energético dependente da Rússia, portanto, o Cáucaso recebeu prioridade geopolítica dos Estados Unidos e de seus aliados e, deste modo, a Geórgia se afigurou para o Ocidente como porta de entrada para o enorme potencial energético do Mar Cáspio. A aproximação da Geórgia com União Europeia e OTAN fez com que o capital ocidental entrasse no país, principalmente nas áreas de construção de gasodutos e oleodutos (Azerbaijão 2016). Cabe esclarecer que a Rússia interpretou a penetração ocidental no Cáucaso como ameaça, pois o estabelecimento de rotas de fornecimento energético (pelo Cáucaso) comprometiam seus objetivos de controlar a oferta de petróleo e gás à Europa. Para Kochladze (2017), as novas vias de transporte de bens energéticos minariam os objetivos de Moscou de monopolizar as rotas de fornecimento de petróleo e gás da Ásia para a Europa. De acordo com o autor, as receitas provenientes do gás natural e do petróleo correspondiam em torno da metade do orçamento russo. Portanto, a aproximação entre Ocidente e Geórgia não foi interessante para a Rússia e, em resposta, como afirma Saakashvili (2010), caberia a Moscou fazer todo o possível para prevenir que a Geórgia se integrasse ao Ocidente. Em síntese, a Geórgia, assim como a Ucrânia, representa interesses estratégicos fundamentais para a Rússia.

\section{CONCLUSÃO}

Para ser possível inferir que a crise da Geórgia e da Ucrânia foram responsabilidade do Ocidente, foi preciso identificar as variáveis que, para Mearsheimer (2014), conferiram a responsabilidade pela crise da Ucrânia ao Ocidente. Para o referido autor, são três variáveis-centrais, a saber: avanço da OTAN, "promoção da democracia”, e expansão da União Europeia.

Nessa lógica de raciocínio, buscou-se identificar a presença desses fatores na culminação, também, na crise da Geórgia. Constatou-se que as mesmas três causas se manifestaram no caso da Geórgia. Assim, a hipótese 
inicial foi comprovada: a crise da Geórgia, por análise comparativa com a crise da Ucrânia, foi, também, responsabilidade do Ocidente. A construção desta conclusão foi assentada em duas premissas: a crise da Ucrânia foi culpa do Ocidente, segundo Mearsheimer (2014); e os fatores que causaram a crise da Ucrânia se manifestaram, também, na crise da Geórgia. Ainda, deve-se destacar que a tríade comportamental: medo, autoajuda e maximização do poder, defendida por Mearsheimer (2001) estão presentes nas ações russas nas duas crises aqui estudadas - conforme defende a teoria realista ofensiva. Ao constatar que Ucrânia e Geórgia representavam interesse estratégico fundamental para a Rússia, ou seja, interesses estratégicos fundamentais de um Estado, Mearsheimer (2015) entende que o Ocidente se aproximou da Geórgia e da Ucrânia, num nível que a Rússia considerava além do aceitável. Por isso, a Rússia adotou respostas (atitudes defensivas) para conter o "avanço do Ocidente" e poder ter assegurados seus interesses (estratégicos) nos dois países.

Conclui-se, portanto, que as crises da Geórgia e da Ucrânia (por comparação) tiveram condicionantes bastante semelhantes, de acordo com as variáveis apresentadas por Mearsheimer (2014) e ambas são resultantes das ações iniciais e expansionistas do Ocidente e que (diferentemente do apresentado pelos Estados Unidos e seus aliados) as atitudes russas foram eminentemente defensivas.

\section{REFERÊNCIAS}

Almeida, João Marques. 2008. "A União Europeia e a Rússia após a crise da Geórgia o fim do paradigma do pós-Guerra Fria". Relações Internacionais, 20, 17-29. http://www.scielo.mec.pt/scielo.php? script=sci_arttext\&pi$\mathrm{d}=\mathrm{S} 1645-91992008000300002 . p t$.

Antelava, Natalia. 2003. How to Stage a Revolution. Londres: BBC News. http:// news.bbc.co.uk/2/hi/europe/3288547.stm.

Archick, Kristin, and Vincent Morelli. 2014. European Union Enlargement. Washington: Congressional Research Service. https://www.fas.org/sgp/crs/row/ RS2 1344.pdf.

Azerbaijão. 2016. Baku-Tbilisi-Ceyhan Pipeline Project. Baku: Azerbaijan Realities. http://a-r.az/en/node/224\#.WCzMb9UrLFg.

Bandeira, Luiz. 2013. A Segunda Guerra Fria. Rio de Janeiro: Civilização Brasileira.

BBC. 2009. Georgia 'Started Unjustified War'. Londres: BBC News. http://news. bbc.co.uk/2/hi/europe/8281990.stm. 
BBC. 2013. Huge Ukraine Rally Over EU Agreement Dlay. Londres: BBC News. http://www.bbc.com/news/world-europe-25078952.

BBC. 2014. Timeline: Ukraine Crisis. Londres: BBC News. http://www.bbc.com/ news/world-middle-east-26248275.

BBC. 2015. Profile: European Union. Londres: BBC News. http://www.bbc.com/ news/world-europe-18788906.

Costa, Wanderley Messias. 2015. "O reerguimento da Rússia, os EUA/OTAN e a crise da Ucrânia: a Geopolítica da nova Ordem Mundial”. Confins [En ligne ], 25. http://journals.openedition.org/confins/10551; DOI: 10.4000/confins. 10551.

European Comission. 2017a. Eastern Partnership. Bruxelas: European Comission. http://ec.europa.eu/dgs/home-affairs/what-we-do/policies/international-affairs/eastern-partnership/index_en.htm.

European Comission. 2017b. European Neighborhood Policy. Bruxelas: European Comission. http://ec.europa.eu/enlargement/neighbourhood/overview/index_ en.htm.

European Union. 2003. A Secure Europe in a Better World. Buxelas: European Security Strategy. https://www.consilium.europa.eu/uedocs/cmsUpload/78367.pdf.

European Union. 2009. Independent International Fact-Finding Mssion on the Conflict in Georgia Report. Bruxelas: European Council v. 1. http://news.bbc.co.uk/2/sha$\mathrm{red} / \mathrm{bsp} / \mathrm{hi} / \mathrm{pdfs} / 30 \_09 \_09 \_$iiffmgc_report.pdf.

European Union. 2017a. Eastern Partnership. Bruxelas: European Union External Action. https://eeas.europa.eu/topics/eastern-partnership/419/eastern-partnership_en.

European Union. 2017b. EU-Ukraine Association Agrement: Quick Guide to Association Agreement. Bruxelas: European Union. https://eeas.europa.eu/sites/ eeas/files/071215_eu-ukraine_association_agreement.pdf.

European Union. 2017c. Factsheet EU-Georgia Rlations. Bruxelas: European Union External Action. http://eeas.europa.eu/archives/docs/factsheets/docs/eu-georgia_factsheet_en.pdf.

Fairbanks, Charles. 2004. "Georgia's Rose Revolution”. Washington: Journal of Democracy 15, no. 2, 110-124. https://muse.jhu.edu/article/54669.

Gallis, Paul. 2008. The NATO Summit at Bucharest, 2008. Washington: CRS Report for Congress. https://www.fas.org/sgp/crs/row/RS22847.pdf. 
Gallis, Paul et al. 2008. Enlargement Issues at NATO's Bucharest Summit. Washington: CRS Report for Congress. https://www.fas.org/sgp/crs/row/RL34415.pdf.

Gordon, Michael. 1997. "The Anatomy of a Misunderstanding”. Nova York: The New York Times. http://www.nytimes.com/1997/05/25/weekinreview/the-anatomy-of-a-misunderstanding.html.

Gressel, Gustav. 2017. Keeping up Appearances: how Europe is Supporting Ukraine's Transformation. Londres: European Council on Foreign Relations. http://www. ecfr.eu/publications/summary/16616.

Hille, Kathrin. 2014. "Ukranian Port is Key to Russia’s Naval Power: Moscow Relies on Sevastopol Black Sea Base for Regional Security”. Londres: Financial Times. https://www.ft.com/content/1f749b24-9f8c-11e3-b6c7-00144feab7de.

King, Charles. 2008. The Five-Day War: Managing Moscow after the Georgia Crisis. Nova York: Foreign Affairs. https://www.foreignaffairs.com/articles/russia-fsu/2008-11-01/five-day-war.

Kochladze, Manana. 2017. Geopolitics of South Caucasus. Colônia: Heinrich Böll Stiftung. https://ge.boell.org/en/2017/04/01/geopolitics-south-caucasus-georgia-and-oil-prices.

Marshall, Tim. 2015a. Prisoners of Geography. Nova York: Scribner.

Marshall, Tim. 2015b. Russia and the Curse of Geography: Want to Understand Why Putin Does What he Does? Look at a Map. Washington: The Atlantic. http://www. theatlantic.com/international/archive/2015/10/russia-geography-ukraine-syria/413248/.

Mearsheimer, John. 2001. The Tragedy of Great Power Politics. Nova York: Norton and Company.

Mearsheimer, John. 2014. Why the Ukraine Crisis is the West's Fault: the Liberal Delusions that Provoked Putin. Nova York: Foreign Affairs. https://www.foreignaffairs.com/articles/russia-fsu/2014-08-18/why-ukraine-crisis-west-s-fault.

Mearsheimer, John. 2015. An Offensive Realist's View of China and Crimean Crisis. Tóquio: Tokyo Foundation Forum. https://www.youtube.com/watch?v=3ZV97GUdHzA.

Mearsheimer, John. 2017. The Causes and Consequences of the Ukraine Crisis. Chicago: Universidade de Chicago. https://www.youtube.com/watch?v=JrMiSQAGOS4. 
Mielniczuk, Fabiano. 2014. "A Crise Ucraniana e suas Implicações para as Relações Internacionais". Conjuntura Austral 5, no. 23, 4-19. https://seer.ufrgs.br/ ConjunturaAustral/article/view/46849/29136.

Mydans, Seth. 2003. Georgian Leader Agrees to Resign, Ending Standoff. Nova York: The New York Times. http://www.nytimes.com/2003/11/24/world/georgian-leader-agrees-to-resign-ending-standoff.html.

NATO. 2008. A Bucharest Summit Declaration. Bucareste: NATO. http://www.nato. int/cps/en/natolive/official_texts_8443.htm.

NATO. 2014. A Short History of NATO. Bruxelas: NATO. http://www.nato.int/ history/nato-history.html.

Osce. 2004. Georgia Parliamentary Elections 2 november 2003: OSCE/ODIHR Election Observation Mission Report, part 1. Varsóvia: Office for Democratic Institutions and Human Rights. http://www.osce.org/odihr/elections/georgia/22206?download=true.

Park, Jeanne. 2014. The European Union's Eastern Partnership. Nova York: Council on Foreign Relations. http://www.cfr.org/europe/european-unions-eastern-partnership.

Plekhanov, Sergei. 2015. "Assisted Suicide: Internal and External Causes of the Ukrainian Crisis". In: Black, Joseph; and Michael Johns. The Return of the Cold War: Ukraine, the West and Russia. Nova York: Routledge.

Reisman, Michael. 2004. "Why Regime Change is (Almost Always) a Bad Idea". Washington: The American Journal of International Law 18, no. 3, 516-525. http:// www.jstor.org/stable/3181642?seq=1\#page_scan_tab_contents.

Rezende, Lucas Pereira. 2014. "Teoria Realista Ofensiva de Cooperação em Defesa na Unipolaridade”. Contexto int. [online] 36, no. 2, 519-548. http://dx.doi. org/10.1590/S0102-85292014000200007.

Rinnert, David. 2011. The Eastern Partnership in Georgia: Icreasing Efficiency of EU Neighborhood Policies in the South Caucasus? Berlim: German Institute for International and Security Affairs, Working Paper FG 5, no. 1. https:// www.swp-berlin.org/fileadmin/contents/products/arbeitspapiere/Rinnert_ EUEasternPartnershipGeorgia.pdf.

RT. 2014. La "conquista" de Europa por la OTAN: una sucesión de pequeñas traiciones. RT News. https://actualidad.rt.com/actualidad/view/124304-otan-rusia-europa-ampliacion. 
Saakashvili, Mikheil. 2010. Why Georgia Matters. Londres: Chatham House. https://www.chathamhouse.org/events/view/156323.

SlideShare. 2011. A União Europeia. SlideShare. https://pt.slideshare.net/geografias/a-unio-europeia-6746860.

Sussman, Gerald, and Sascha Krader. 2008. Template Revolutions: Marketing U.S. Regime Change in Eastern Europe. Westminster: Westminster Papers in Communication and Culture 5, no. 3, 91-112. https://www.westminster.ac.uk/ file $/ 7561 /$ download? token $=$ CYB8Szpq.

Talbott, Strobe. 1995. Why Nato Should Grow. Nova York: The New York Review of Books. http://www.nybooks.com/articles/1995/08/10/why-nato-should-grow/.

Trucker, Joshua. 2007. "Enough! Electoral Fraud, Collective Action Problems, and Post-Communist Colored Revolutions". Cambridge: Perspectives on Politics 5, no. 3, 535-551. https://www.cambridge.org/journals/perspectives-on-politics/ article/enough-electoral-fraud-collective-action-problems-and-post-communist-colored-revolutions/7D77E56D2AC79DBCEB649CE698BA5584.

Ukraine. 2015. Association Agreement Between the European Union and Ukraine. Kiev: Ukranian Government Portal. http://www.kmu.gov.ua/control/en/publish/article\%3Fart_id=248279225\&cat_id=248274610.

United States. 1995. A National Security Strategy of Engagement and Enlargement. Washington: The White House. http://www.dtic.mil/doctrine/doctrine/research/nss.pdf. 


\section{O OCIDENTE COMO RESPONSÁVEL PELAS CRISES \\ DA UCRÂNIA E DA GEÓRGIA}

\section{RESUMO}

Em 2008, a Rússia interveio na Geórgia e reconheceu a independência das províncias separatistas da Ossétia do Sul e da Abecásia. Em 2014, a Rússia promoveu ação militar na Ucrânia e anexou a península da Crimeia ao território russo. Tomando como foco de análise estes dois fatos históricos, o presente trabalho tem como objetivo comparar as crises da Ucrânia e da Geórgia, a fim de demonstrar que ambas as crises têm suas responsabilidades dadas às ações do Ocidente. Em termos metodológicos, foi realizada uma análise comparativa entre as duas crises, utilizando-se o ponto de vista do pensamento realista e da teoria do realismo ofensivo. Como resultado da presente análise, constatou-se que as variáveis - com base nas quais Mearsheimer (2014) afirma que a crise da Ucrânia foi responsabilidade do Ocidente - manifestaram-se na Geórgia. Desse modo, a conclusão desse trabalho indica que a crise da Geórgia, de 2008, também teve o Ocidente como seu principal responsável. Essa conclusão está baseada na existência das variáveis: avanço da OTAN; promoção da "democracia" Ocidental; e expansão da União Europeia, apresentadas por Mearsheimer (2001; 2014), a presença da tríade comportamental (medo, autoajuda e maximização do poder) e as estratégias (de defesa) russas às regiões em estudo. Nesse sentido, e diferentemente do que é afirmado pelo Ocidente, a Rússia teve, em ambas as crises, papel eminentemente defensivo.

Palavras-chave: Ocidente; Crise da Ucrânia; Crise da Geórgia; Rússia.

\section{ABSTRACT}

In 2008, Russia intervened in Georgia and recognized the independence of the separatist provinces of South Ossetia and Abkhazia. In 2014, Russia promoted military action in Ukraine and annexed the Crimean Peninsula to Russian territory. Taking the focus of the analysis of these two historical facts, the present research aims to verify if the argument of Mearsheimer (2014), according to which the crisis of Ukraine was the responsibility of the West, is applicable to the crisis of Georgia. In methodological terms, a comparative analysis was carried out between the two crises using the point of view of realistic thinking and the theory of offensive realism. As a result of the research, it was found that the variables on the basis of which Mearsheimer (2014) states that the crisis of Ukraine 
was the responsibility of the West were manifested in Georgia. According to Mearsheimer $(2001,2014)$ and the presence of the behavioral triad (fear), the conclusion is that the Georgian crisis of 2008, according to the variables (NATO advancement, democracy promotion and EU expansion), self-help and maximization of power, also had the West as main responsible. Accordingly, and contrary to what is stated by the West, Russia had, in both crises, absolutely defensive role.

Keywords: West; Ukraine’s crisis; Georgia's crisis; Russia. 